\title{
Evaluating research productivity: a case study of the rice scientists in India and Sri Lanka
}

\author{
Seetha I. Wickremasinghe \\ Science \& Technology Policy Research Division, National Science Foundation, 47/5, Maitland Place, Colombo-07.
}

\begin{abstract}
Measuring research productivity of the scientific community is important because it gives an insight to the research and development (R\&D) of a particular country. A common method used for this purpose is the evaluation of the output of the research publications viz., research articles published in the journals and bulletins; presentations at workshops/ conference proceedings; books or chapters in books; technical reports etc. The patents and the awards received by the scientists are also considered as research productivity indicators. The present case study is aimed at evaluation of the research productivity of rice scientists in India and Sri Lanka through their publications and other research outputs. A questionnaire survey was administered among the scientists at the Central Rice Research Institute (CRRI), at Cuttack in the Orissa State of India and at the Rice Research and Development Institute (RRDI), at Batalagoda, Ibbagamuwa in Sri Lanka. This was supplemented by direct interviews with senior scientists and research administrators in the National Agricultural Research Systems (NARS) in both countries. The mean research productivity was found to be significantly higher $(p \leq 1)$ for Indian rice scientists compared to the Sri Lankan rice scientists. The possible reasons for this difference that emerged from this study are as follows. a) Publication of research is the most essential criterion for promotion and career development of Indian scientists; b) Many Indian journals are available for publication of rice research; and c) The majority of Indian rice scientists hold $\mathrm{PhD}$ degrees which is essential for conducting independent research. The study also indicated a policy insight for training Sri Lankan rice scientists up to $\mathrm{PhD}$ level for higher research productivity.
\end{abstract}

Keywords: India, research productivity, research publication, rice research, rice scientists, science policy, science \& technology output, Sri Lanka.

\section{INTRODUCTION}

The contribution of research productivity of scientists towards the socio-economic development of a country is well accepted. However, the research productivity of scientists is characterized by an extremely unequal distribution. This property adds a special interest to the analysis since it leads to a better understanding of its determinants. One of the best known theories to explain the existing inequality in research productivity is the Cumulative Advantage Theory (Mathew effect) ${ }^{1}$. According to this theory, scientists or researchers become more or less productive based on the incidence of a sequence of events taking place in their scientific careers viz., the quantity and quality of training, mentor's research performance, collaboration with other scientists, the prestige of the departments in which they work and the amount of funding that they receive $^{2}$. There are other related determinants of research productivity such as motivation or gender, with latter being possibly associated to a cumulative disadvantage process (Matilda effect). Lehman ${ }^{3}$ reported that the major contributions of scientists occur in their late $30 \mathrm{~s}$ and early 40s with a decline thereafter. A possible reason for the decline may be the scientists tending to take up managerial and administrative positions with less involvement in research activities. Other studies have shown that high-impact research articles were produced by researchers who were within ten years of doctoral graduation ${ }^{4}$. Some have reported that the research productivity of an organization mostly depends on a few members (perhaps less than 20\%) and they produce more than half the publications representing the organization as a whole ${ }^{5}$. Others argue that scholarly impact or research productivity is independent of age and the conditions governing technical contributions appear to transcend cultural boundaries and political systems ${ }^{6}$.

In evaluating research productivity of a scientific community, publication of research findings is the most common measure which is being considered at present, even though it is not the most accurate indicator. It is 
now argued that gaps and shortcomings could exist in evaluating research productivity of scientists only through their publications. This may be due to the complex nature of the changing world in the present time where factors other than scientific productivity also exert a major influence on scientific career development. Although publication of research findings is very important to gain scientific recognition and identity towards professionalization of the scientific community in a particular country, it should not be the main and the only criteria for evaluation of research productivity of the scientific community ${ }^{7}$. However, one must accept the fact that publication of research avoids duplication or repetitions of similar kinds of research which otherwise leads to the wastage of money and other resources. According to Allison (1980), the most fundamental social processes of science are the communication and exchange of research findings and results ${ }^{8}$. The principal means of scientific communication is the publication process, which allows scientists to verify the reliability of information, to acquire a sense of relative importance of a contribution, and to obtain critical response to work ${ }^{9}$. It is an accepted fact that scientists receive professional recognition and esteem, as well as promotion, advancement, and funding for future research through their publications ${ }^{10}$. Publication is so central to the productivity in research that the work becomes 'a work' only when it takes a conventional and physical (that is, published) form which can be received, assessed, and acknowledged by the scientific community ${ }^{11}$. More recognition a scientist receives by rewards for his or her publications, more productive he or she will become subsequently ${ }^{12}$. Measuring research productivity through outputindicators has been useful not only to evaluate the contribution of the scientific community, but also to get an insight as to how far a country has progressed in R\&D for the betterment of socio-economic aspects of the nation.

Research on rice is crucial to many countries in Asia. Rice is important to India and because it is the staple food for $65 \%$ of the population in India. In Sri Lanka rice is the only source of staple food consumed by the majority of people. An increased and sustained production of rice through conventional and advanced research is fundamental to food security in both the countries. This study was, therefore, designed to evaluate the research productivity of rice scientists in India and Sri Lanka with special reference to their publications and other research outputs such as patents and awards.

\section{METHODS \& MATERIALS}

Two case studies were conducted in 2003 for India and Sri Lanka using a structured questionnaire which was distributed among scientists at the Central Rice
Research Institute (CRRI) in India and Rice Research and Development Institute (RRDI) in Sri Lanka. The two studies were supplemented with direct interviews with the senior scientists and research administrators in the National Agricultural Research Systems (NARS) of both countries.

The CRRI (India) is located at Cuttack $\left(20^{\circ} \mathrm{N}, 86^{\circ} \mathrm{E}\right)$, in the Orissa State, $23 \mathrm{~m}$ above mean sea level and about $35 \mathrm{~km}$ from the Bhubaneswar airport and $7 \mathrm{~km}$ from the Cuttack railway station on the Cuttack-Paradeep State Highway. The RRDI (Sri Lanka) is located at Batalagoda, $10 \mathrm{~km}$ north of Kurunegala on the Colombo-Trincomalee main road.

\section{1) Data Sampling:}

a) Questionnaire survey- CRRI (India) had 93 scientists, who were actively involved in R\&D at the time of the questionnaire survey, and a sample size of $50 \%$ was taken for the study. RRDI (Sri Lanka) had only 21 scientists who were actively involved in R\&D at the time of the questionnaire survey so the total population was considered.

b) Direct interviews- In addition to the above, a sample of 25 scientists from each country was selected representing research institutes, universities and government departments in the NARS.

2) Analysis of data: First a descriptive statistical analysis was performed to identify the initial patterns of the data on all qualitative and quantitative variables included in the structured questionnaire. Simple tabulation of data with percentage values along with the mean values was used for comparison of the research productivity of rice scientists in the two countries. To calculate an accurate measure of productivity of scientists in the two rice research institutes in India and Sri Lanka, a weighted sum of prestige scores in the range of 1-5 (Likert scale) was given to each item viz. journals, books, technical reports etc. as has been done by the other studies published on scientific/research productivity ${ }^{13-15}$. The Research Productivity (RP) of rice scientists was calculated according to the following principle;

\section{Research Productivity (RP) = Total research output / Experience in the Institute}

Total research output was measured using two ranking methods as given below:

1. by giving highest scores to publications in international journals and conference proceedings

2. by giving highest scores to publications in local journals and conference proceedings 
Score ranking methods used to measure the research output are indicated below.

\begin{tabular}{llll}
\hline & & \multicolumn{2}{c}{ Ranking } \\
Item / category of contribution & method I & method II \\
\hline & & 5 & 4 \\
i. & International refereed journals (authored) & 3 & 2 \\
ii. $\quad$ International non refereed journals (authored) & 4 & 5 \\
iii. $\quad$ Local refereed journals (authored) & 2 & 3 \\
iv. $\quad$ Local non refereed journals (authored) & 4 & 3 \\
v. $\quad$ International refereed journals (co-authored) & 2 & 1 \\
vi. $\quad$ International non refereed journals (co-authored) & 3 & 4 \\
vii. $\quad$ Local refereed journals (co-authored) & 1 & 2 \\
viii. $\quad$ Local non refereed journals (co-authored) & 4 & 3 \\
ix. $\quad$ International conference proceedings (authored) & 3 & 4 \\
x. $\quad$ Local conference proceedings (authored) & 3 & 2 \\
xi. $\quad$ International conference proceedings (co-authored) & 2 & 3 \\
xii. $\quad$ Local conference proceedings (co-authored) & 5 & 5 \\
xiii. $\quad$ Books & 3 & 3 \\
xiv. $\quad$ Book chapters & 2 & 2 \\
xv. $\quad$ Bulletins and technical reports & 5 & 5 \\
xvi. $\quad$ Foreign patents & 4 & 4 \\
xvii. Local patents & 5 & 5 \\
xviii. International awards & 4 & 4 \\
xix. Local awards & & 5
\end{tabular}

The research productivity was calculated using both ranking methods of weighted score. The Mean Research Productivity (MRP) for each country was calculated by adding the research productivity value for each scientist in the respective institute and dividing the same by the sample size of the institute. The difference in MRP was used for the t-test to compare the research productivity of the two institutes.

The qualitative data gathered through the open-ended direct interviews were also carefully analyzed according to Yin $^{16}$ and Wengraf ${ }^{17}$. For this purpose, the responses relevant to each question by various respondents were taken into consideration and summarized before arriving at conclusions.

\section{RESULTS AND DISCUSSION}

The background information relevant to the two institutions, the personnel information and educational qualifications of the rice scientists included in the study in India and Sri Lanka are discussed first. Next, the research output and the productivity calculated based on the said research output of scientists in the two countries are presented.

Distribution of rice scientists using the parameters of designation, age, total research and development (TRD) experience, and years of experience in rice research relevant to India and Sri Lanka are presented in the Table 1.

\section{Personnel information}

The majority of the scientists in the sample of the CRRI (India) was in the category of principal scientists while the majority of scientists in the RRDI (Sri Lanka) was in the category of scientists-Grade I, equivalent to the principal scientists at CRRI (Table 1). The direct interviews with the Indian scientists revealed that the recruitment and promotion scheme of the Indian agricultural scientists had been revised recently to provide an avenue for the scientists to get promoted to the principal scientist grade. This was the major reason for the number of principal scientists in the CRRI (India) being comparatively higher compared to the number of the senior scientists and the scientists at RRDI (Sri Lanka). There was no principal scientist position in the NARS of Sri Lanka but the equivalent position was the Grade I Scientist. It was revealed that the scientists at RRDI (Sri Lanka) have been affected due to the shortcomings of the Recruitment and Promotion Scheme of the Department of Agriculture (DOA) which lacked proper avenues for further promotions.

The age of Indian rice scientists in the sample ranged from 34 - 61 years and that of Sri Lankan rice 
Table 1: Distribution of rice scientists using the parameters designation, age, total R\&D (TRD) experience and years of experience in rice research in India and Sri Lanka

\begin{tabular}{|c|c|c|}
\hline \multirow[t]{3}{*}{ Parameter } & \multicolumn{2}{|c|}{ Distribution of scientists } \\
\hline & CRRI (India) & RRDI (Sri Lanka) \\
\hline & No. $(\%)$ & No. $(\%)$ \\
\hline \multicolumn{3}{|l|}{ Designation } \\
\hline Principal scientists* & $26(60.5)$ & $7 \quad(33.3)$ \\
\hline Senior scientists & $10(23.3)$ & $9 \quad(42.9)$ \\
\hline Scientists & 7 (16.4) & $5(23.8)$ \\
\hline Total & $43(100.0)$ & $21(100.0)$ \\
\hline \multicolumn{3}{|l|}{ Age (years) } \\
\hline $31-40$ & $5 \quad(12)$ & $2(9)$ \\
\hline $41-50$ & $14 \quad(33)$ & $14(67)$ \\
\hline $51-60$ & $23 \quad(53)$ & $5(24)$ \\
\hline 61-above & $1 \quad(2)$ & $0(0)$ \\
\hline Total & $43(100)$ & $21(100)$ \\
\hline \multicolumn{3}{|c|}{ Total R\&D experience (years) } \\
\hline $1-5$ & $0 \quad(0)$ & $3(14)$ \\
\hline $6-10$ & $4 \quad(9)$ & $0 \quad(0)$ \\
\hline $11-15$ & $3 \quad(7)$ & $0 \quad(0)$ \\
\hline $16-20$ & $1 \quad(2)$ & $9(43)$ \\
\hline $21-25$ & $7(16)$ & $8(38)$ \\
\hline $26-30$ & $18(43)$ & $1(5)$ \\
\hline 31-above & $10(23)$ & $0(0)$ \\
\hline Total & $43(100)$ & $21(100)$ \\
\hline \multicolumn{3}{|c|}{ Experience in rice research (years) } \\
\hline $1-5$ & $3 \quad(7)$ & $9(43)$ \\
\hline $6-10$ & $5(12)$ & $0 \quad(0)$ \\
\hline $11-15$ & $4 \quad(9)$ & $1(5)$ \\
\hline $16-20$ & $3 \quad(7)$ & $3(14)$ \\
\hline $21-25$ & $10(23)$ & $8(38)$ \\
\hline $26-30$ & $13(30)$ & $0(0)$ \\
\hline 31-above & $5(12)$ & $0(0)$ \\
\hline Total & 43 (100) & $21(100)$ \\
\hline
\end{tabular}

* at RRDI(Sri Lanka), Grade I Scientist is equivalent to Principal Scientist at CRRI(India)

scientists ranged from 31 - 55 years (Table 1). The age of retirement of Indian agricultural scientists at the time of the Survey was 60 years (now extended up to 62 years), though very rarely a few exceptional cases were seen as personal to the holder. The age of retirement of the Sri Lankan agricultural scientists was 57 years at the time of the survey, which may be extended up to 60 years on request and approved on a case by case basis.

In the CRRI (India), nearly $84 \%(16+43+23)$ of scientists were very senior scientists who had more than 20 years of total $R \& D$ experience in the agriculture sector (Table 1) and in Sri Lanka, there were only $43 \%$ $(38+5)$ of scientists with more than 20 years of total R\&D experience in the agriculture sector. Table 1 also shows that the total $R \& D$ experience of rice scientists in the
CRRI (India) ranged from 1 - 37 years and at the RRDI (Sri Lanka) it ranged from 1 - 25 years. The CRRI (India) had $72 \%$ scientists with more than 20 years of experience while at RRDI (Sri Lanka) only 38\% scientists had more than 20 years of experience in the institute. The highest percentage (43\%) of scientists in the RRDI (Sri Lanka) had less than 5 years of experience in the institute.

The direct interviews indicated that the Sri Lankan rice scientists have comparatively a few years of experience in rice research due to frequent transfers as a matter of routine policy. According to some scientists in the RRDI (Sri Lanka) these transfers have affected their crop specialty research, and lowered their research productivity. The other reason, for RRDI (Sri Lanka) having only a few experienced scientists could be due to 
senior scientists taking up higher administrative positions at other related institutes in the DOA. Some have left for overseas employment while others have joined the universities.

\section{Educational Qualifications}

The distribution of rice scientists by the level of education in India and Sri Lanka is presented in Table 2.

Majority (86\%) of Indian rice scientists had $\mathrm{PhD}$ degrees (Table 2). Direct interviews revealed that a Masters degree in agriculture or science and technology is a basic requirement to join a research institute in India. In Sri Lanka, the basic requirement to join a research institute as a scientist is only a Bachelors degree. All six (06) Indian scientists from the CRRI (India) who took part in the survey were Agricultural Engineers with MSc degrees and they were of the view that their qualifications were adequate for research purposes. There were no agricultural engineers attached to the RRDI (Sri Lanka) because a separate unit had been established to serve the engineering needs of all the institutes of the DOA.

\section{Research output (publications) of rice scientists in India and Sri Lanka}

Journals: When publishing research in international journals the rice scientists in both countries had considered only refereed international journals (Table 3). Out of 43 scientists in CRRI in India, 70\% scientists $(54+14+2=70 \%)$ had published at least one research paper in a refereed international journal compared to $48 \%$ scientists $(43+5=48 \%)$ in the RRDI in Sri Lanka. All 43 scientists $(100 \%)$ in the CRRI had published at least one paper in a refereed local journal with the number of publications varying from 1 to 16 and above. In the case of Sri Lanka only $62 \%(52+10=62 \%)$ of scientists had publications in refereed local journals.

About $79 \%(67+7+5=79 \%)$ of scientists in the CRRI (India) had co-authored at least one publication

Table 2: Frequency distribution of Indian and Sri Lankan rice scientists by the level of education

\begin{tabular}{llc}
\hline \multirow{2}{*}{ Level of education } & \multicolumn{2}{c}{ Distribution of rice scientists } \\
\cline { 2 - 3 } & \multicolumn{1}{c}{ India } & Sri Lanka \\
& No. $(\%)$ & No. $(\%)$ \\
\hline PhD & $37(86.5)$ & $6(28.5)$ \\
MPhil & $0(0)$ & $4(19.5)$ \\
MSc & $6(13.95)$ & $6(28.5)$ \\
BSc & $0(0)$ & $4(19.5)$ \\
ND* & $0(0)$ & $1(4.76)$ \\
Total & $\mathbf{4 3 ( 1 0 0 )}$ & $\mathbf{2 1}(\mathbf{1 0 0})$ \\
\hline
\end{tabular}

ND* - no degree, but promoted based on experience

Table 3: Frequency distribution of rice scientists in CRRI (India) and RRDI (Sri Lanka) based on journal publications (main authorship)

\begin{tabular}{|c|c|c|c|c|c|c|c|c|}
\hline \multirow{5}{*}{$\begin{array}{l}\text { Number of papers } \\
\text { published }\end{array}$} & \multicolumn{8}{|c|}{ Distribution of rice scientists } \\
\hline & \multicolumn{4}{|c|}{ India } & \multicolumn{4}{|c|}{ Sri Lanka } \\
\hline & \multicolumn{2}{|c|}{ International } & \multicolumn{2}{|c|}{ Local } & \multicolumn{2}{|c|}{ International } & \multicolumn{2}{|c|}{ Local } \\
\hline & $\mathrm{R}$ & NR & $\mathrm{R}$ & NR & $\mathrm{R}$ & NR & $\mathrm{R}$ & NR \\
\hline & No. $(\%)$ & No. $(\%)$ & No. $(\%)$ & No. $(\%)$ & No. $(\%)$ & No. $(\%)$ & No. $(\%)$ & No. $(\%)$ \\
\hline None & $13(30)$ & $0(0)$ & $0(0)$ & $30(70)$ & $11(52)$ & $0(0)$ & $8(38)$ & $16(76)$ \\
\hline $1-5$ & $23(54)$ & $0(0)$ & $12(28)$ & $10(23)$ & $9(43)$ & $0(0)$ & $11(52)$ & $3(14)$ \\
\hline $6-10$ & $6(14)$ & $0(0)$ & $14(33)$ & $3(7)$ & $1(5)$ & $0(0)$ & $2(10)$ & $2(10)$ \\
\hline $11-15$ & $1(2)$ & $0(0)$ & $10(23)$ & $0(0)$ & $0(0)$ & $0(0)$ & $0(0)$ & $0(0)$ \\
\hline 16-above & $0(0)$ & $0(0)$ & $7(16)$ & $0(0)$ & $0(0)$ & $0(0)$ & $0(0)$ & $0(0)$ \\
\hline Total & $43(100)$ & $0(0)$ & $43(100)$ & $43(100)$ & $21(100)$ & $0(0)$ & $21(100)$ & $21(100)$ \\
\hline
\end{tabular}

R- Refereed; NR- Non-Refereed 
in a refereed international journal compared to only $19 \%$ $(14+5=19 \%)$ of scientists in the RRDI (Sri Lanka) as indicated in Table 4. In the case of local publications, $77 \%$ of scientists $(28+26+23=77 \%)$ in the CRRI (India) had co-authored at least one publication in refereed local journals compared to $38 \%$ of scientists $(33+5=38 \%)$ in the RRDI (Sri Lanka).

With regard to publication of research in journals, the rice scientists in the CRRI (India) are far ahead compared to scientists in the RRDI (Sri Lanka) (Table $3 \& 4$ ).

Table 4: Frequency distribution of rice scientists in CRRI (India) and RRDI (Sri Lanka) based on journal publications (co-authorship)

\begin{tabular}{|c|c|c|c|c|c|c|c|c|}
\hline \multirow{5}{*}{$\begin{array}{l}\text { Number of papers } \\
\text { published }\end{array}$} & \multicolumn{8}{|c|}{ Distribution of rice scientists } \\
\hline & \multicolumn{4}{|c|}{ India } & \multicolumn{4}{|c|}{ Sri Lanka } \\
\hline & \multicolumn{2}{|c|}{ International } & \multicolumn{2}{|c|}{ Local } & \multicolumn{2}{|c|}{ International } & \multicolumn{2}{|c|}{ Local } \\
\hline & $\mathrm{R}$ & NR & $\mathrm{R}$ & NR & $\mathrm{R}$ & NR & $\mathrm{R}$ & NR \\
\hline & No. $(\%)$ & No. $(\%)$ & No. $(\%)$ & No. (\%) & No. $(\%)$ & No. $(\%)$ & No. $(\%)$ & No. (\%) \\
\hline none & $9(21)$ & $0(0)$ & $10(23)$ & $0(0)$ & $17(81)$ & $0(0)$ & $13(62) 2$ & $0(95)$ \\
\hline $1-5$ & $29(67)$ & $0(0)$ & $12(28)$ & $0(0)$ & $3(14)$ & $0(0)$ & $7(33)$ & $1(5)$ \\
\hline $6-10$ & $3(7)$ & $0(0)$ & $11(26)$ & $0(0)$ & $1(5)$ & $0(0)$ & $1(5)$ & $0(0)$ \\
\hline $11-15$ & $2(5)$ & $0(0)$ & $10(23)$ & $0(0)$ & $0(0)$ & $0(0)$ & $0(0)$ & $0(0)$ \\
\hline 16-above & $0(0)$ & $0(0)$ & $0(0)$ & $0(0)$ & $0(0)$ & $0(0)$ & $0(0)$ & $0(0)$ \\
\hline Total & $43(100 \%)$ & $0(0)$ & $43(100 \%)$ & $0(0)$ & $21(100 \%)$ & $0(0)$ & $21(100 \%)$ & $0(0)$ \\
\hline
\end{tabular}

R- Refereed; NR- Non-Refereed

Table 5: Frequency distribution of rice scientists in CRRI (India) and RRDI (Sri Lanka) based on publication in conference proceedings (authorship)

\begin{tabular}{lrrrr}
\hline \multirow{2}{*}{$\begin{array}{l}\text { Number of papers } \\
\text { published }\end{array}$} & \multicolumn{4}{c}{ Distribution of rice scientists } \\
& \multicolumn{3}{c}{ India } & \multicolumn{2}{c}{ Sri Lanka } \\
\cline { 2 - 5 } & International & Local & International & Local \\
& No. (\%) & No. (\%) & No. (\%) & No. (\%) \\
\cline { 2 - 5 } None & $25(58)$ & $5(12)$ & $14(67)$ & $10(48)$ \\
$1-3$ & $14(33)$ & $20(46)$ & $3(14)$ & $7(33)$ \\
$4-6$ & $3(7)$ & $9(21)$ & $4(19)$ & $4(19)$ \\
$7-9$ & $0(0)$ & $5(12)$ & $0(0)$ & $0(0)$ \\
$10-$ above & $1(2)$ & $4(9)$ & $0(0)$ & $0(0)$ \\
Total & $\mathbf{4 3 ( 1 0 0 )}$ & $\mathbf{4 3 ( 1 0 0 )}$ & $\mathbf{2 1 ( 1 0 0 )}$ & $\mathbf{2 1 ( 1 0 0 )}$ \\
\hline
\end{tabular}

Table 6: Frequency distributions of scientists in CRRI (India) and RRDI (Sri Lanka) based on publication in conference proceedings (co-authorship)

\begin{tabular}{lrrrr}
\hline \multirow{2}{*}{$\begin{array}{l}\text { Number of papers } \\
\text { published }\end{array}$} & \multicolumn{3}{c}{ Distribution of rice scientists } \\
\cline { 2 - 5 } & $\begin{array}{c}\text { India } \\
\text { International } \\
\text { No. (\%) }\end{array}$ & $\begin{array}{c}\text { Local } \\
\text { No. (\%) }\end{array}$ & $\begin{array}{c}\text { International } \\
\text { No. (\%) }\end{array}$ & Local \\
& $19(44)$ & $11(25)$ & $10(48)$ & No. (\%) \\
\cline { 2 - 5 } None & $19(44)$ & $15(35)$ & $9(42)$ & $12(57)$ \\
$1-3$ & $3(7)$ & $10(23)$ & $2(10)$ & $7(33)$ \\
$4-6$ & $1(2)$ & $2(5)$ & $0(0)$ & $2(10)$ \\
$7-9$ & $1(2)$ & $5(12)$ & $0(0)$ & $0(0)$ \\
$10-$ above & $\mathbf{4 3 ( 1 0 0 )}$ & $\mathbf{4 3 ( 1 0 0 )}$ & $\mathbf{2 1 ( 1 0 0 )}$ & $\mathbf{2 1 ( 1 0 0 )}$ \\
Total & & & & $0(0)$ \\
\hline
\end{tabular}


Conference proceedings: About $42 \%$ of scientists $(33+7+2=42 \%)$ in the CRRI (India) had authored at least one publication in an international conference proceedings compared to $33 \%$ of scientists $(14+19=33 \%)$ in the RRDI (Sri Lanka)(Table 5). In the case of local conference proceedings, the relevant figure for India was $88 \%(46+21+12+9=88 \%)$ and for Sri Lanka was $52 \%$ $(33+19=52 \%)$.

About $55 \%$ of scientists $(44+7+2+2=55 \%)$ in the CRRI (India) had co-authored at least one publication in an international conference proceedings while that for the RRDI (Sri Lanka) was 52\% $(42+10=52 \%$ ) (Table 6). In the case of local conference proceedings, it was $75 \%$ $(35+23+5+12=75 \%)$ for India and $43 \%(33+10=43 \%)$ for Sri Lanka. The publications in conference proceedings by scientists at the CRRI (India) therefore, was higher than that of the scientists at the RRDI (Sri Lanka).

Authorship of books and/ or chapters in books by scientists: There was no significant difference between the scientists in the CRRI (India) and the RRDI (Sri Lanka) in publication of books and/or chapters of books, which was $56 \%(40+9+7=56 \%)$ and $52 \%$ $(42+5+5=52 \%)$ respectively (Table 7$)$. Sixty percent of the scientists $(37+14+9=60 \%)$ in the CRRI (India) had at least one bulletin publication or a technical report to their credit. Thus, there was no substantial difference between the two groups as $62 \%$ of scientists $(38+10+14=62 \%)$ in the RRDI (Sri Lanka) also had at least one bulletin publication or a technical report.

\section{Patents obtained by scientists}

Only $2 \%$ of scientists in the CRRI (India) had obtained foreign patents and none by the scientists in RRDI (Sri Lanka). The above patents were in the areas of chemical processing and variety development. In regard to local patents, the numbers were 23 and 15 for Indian and Sri Lankan scientists respectively.

\section{Awards received by scientists}

According to Table 8, only four Sri Lankan scientists $(10 \%)$ had won foreign awards (e.g. Senadhira Memorial International Rice Research Award for outstanding rice scientists; Young Scientists Award for scientists working in Asia, Africa and South America by START Secretariat based in Washington DC) as against one Indian scientist $(2 \%)$ in the CRRI (India). With regard to the local awards, $42 \%$ of Indian scientists had won awards (e.g. Jawaharlal NehruAward; Hooker Award; JewelofIndia Award; Vasvik Award; Chinoy Memorial Award, etc.,) for their research, compared to $20 \%$ of scientists in the RRDI (Sri Lanka) who won local awards (The President's Research Award; National Awards for Agricultural Research Achievement; NSF (National Science Foundation)Merit Award: NSF(National Science Foundation) National Award for Scientific Achievement, etc.,). The reason given by the scientists in the CRRI (India) for having won comparatively fewer foreign awards was that despite their useful research findings, many of them were not interested in applying for foreign awards.

Table 7: Frequency distribution of scientists in CRRI (India) and RRDI (Sri Lanka) based on publication of books and/ or chapters in books, bulletins and technical reports

\begin{tabular}{lrr}
\hline & \multicolumn{2}{c}{ Distribution of rice scientists } \\
\cline { 2 - 3 } $\begin{array}{l}\text { Number of books/bulletins } \\
\text { technical reports }\end{array}$ & India & Sri Lanka \\
& No. (\%) & \\
\hline Books and/ or book chapters & & \\
None & $19(44)$ & $10(48)$ \\
$1-3$ & $17(40)$ & $9(42)$ \\
$4-6$ & $3(7)$ & $1(5)$ \\
$7-$ above & $4(9)$ & $1(5)$ \\
Total & $\mathbf{4 3 ( 1 0 0 )}$ & \\
Bulletins and/or technical reports & & $\mathbf{2 1 ( 1 0 0 )}$ \\
None & $17(40)$ & $8(38)$ \\
$1-3$ & $16(37)$ & $8(38)$ \\
$4-6$ & $6(14)$ & $2(10)$ \\
$7-$ above & $4(9)$ & $3(14)$ \\
Total & $\mathbf{4 3 ( 1 0 0 )}$ & $\mathbf{2 1 ( 1 0 0 )}$ \\
\hline
\end{tabular}


Table 8: Frequency distribution of scientists in CRRI (India) and RRDI (Sri Lanka) based on patents obtained and awards received

\begin{tabular}{lrrrr}
\hline \multirow{2}{*}{$\begin{array}{l}\text { Number of } \\
\text { patents }\end{array}$} & \multicolumn{3}{c}{ Distribution of rice scientists } \\
\cline { 2 - 5 } & $\begin{array}{c}\text { India } \\
\text { International } \\
\text { No. (\%) }\end{array}$ & $\begin{array}{c}\text { Local } \\
\text { No. (\%) }\end{array}$ & International & Local \\
\hline Patents obtained & & & & No. (\%) \\
None & $42(98)$ & $33(77)$ & $21(100)$ & $18(85)$ \\
One & $0(0)$ & $4(9)$ & $0(0)$ & $0(0)$ \\
Two & $1(2)$ & $2(5)$ & $0(0)$ & $1(5)$ \\
Three & $0(0)$ & $0(0)$ & $0(0)$ & $0(0)$ \\
Four \& above & $0(0)$ & $4(9)$ & $0(0)$ & $2(10)$ \\
Total & $\mathbf{4 3 ( 1 0 0 )}$ & $\mathbf{4 3 ( 1 0 0 )}$ & $\mathbf{2 1 ( 1 0 0 )}$ & $\mathbf{2 1 ( 1 0 0 )}$ \\
Awards received & & & & \\
None & $42(98)$ & $25(58)$ & $19(90)$ & $17(81)$ \\
One & $1(2)$ & $10(23)$ & $1(5)$ & $2(10)$ \\
Two & $0(0)$ & $5(12)$ & $0(0)$ & $0(0)$ \\
Three & $0(0)$ & $1(2)$ & $1(5)$ & $1(5)$ \\
Four \& above & $0(0)$ & $2(5)$ & $0(0)$ & $1(5)$ \\
Total & $\mathbf{4 3 ( 1 0 0 )}$ & $\mathbf{4 3 ( 1 0 0 )}$ & $\mathbf{2 1 ( 1 0 0 )}$ & $\mathbf{2 1 ( 1 0 0 )}$ \\
\hline
\end{tabular}

Table 9: Frequency distribution of number of scientists in CRRI (India) and RRDI (Sri Lanka) based on research productivity

\begin{tabular}{|c|c|c|c|c|}
\hline \multirow{2}{*}{$\begin{array}{l}\text { Research productivity } \\
\text { range }\end{array}$} & \multicolumn{2}{|c|}{ India } & \multicolumn{2}{|c|}{ Sri Lanka } \\
\hline & Method I & Method II & Method I & Method II \\
\hline & \multicolumn{2}{|c|}{ number of scientists } & \multicolumn{2}{|c|}{ number of scientists } \\
\hline Less than & 10 & 0 & 3 & 3 \\
\hline $1.0-3.9$ & 12 & 10 & 8 & 7 \\
\hline $4.0-6.9$ & 16 & 13 & 5 & 5 \\
\hline $7.0-9.9$ & 4 & 8 & 3 & 4 \\
\hline $10.0-12.9$ & 6 & 2 & 0 & 0 \\
\hline $13.0-15.9$ & 2 & 6 & 1 & 1 \\
\hline $16.0-18.9$ & 0 & 1 & 0 & 0 \\
\hline $19.0-21.9$ & 2 & 1 & 1 & 0 \\
\hline 22 and above & 1 & 2 & 0 & 1 \\
\hline Total & 43 & 43 & 21 & 21 \\
\hline
\end{tabular}

Table 10: Frequency distribution of percentage (\%) of scientists in CRRI (India) and RRDI (Sri Lanka) based on research productivity

\begin{tabular}{lcc}
\hline $\begin{array}{l}\text { Research productivity } \\
\text { range }\end{array}$ & $\begin{array}{c}\text { India } \\
\text { \% of scientists }\end{array}$ & $\begin{array}{c}\text { Sri Lanka } \\
\text { \% of scientists }\end{array}$ \\
\hline Less than 1 & 0.0 & 14.2 \\
$1.0-3.9$ & 23.3 & 33.3 \\
$4.0-6.9$ & 30.2 & 23.9 \\
$7.0-9.9$ & 18.6 & 19.9 \\
$10.0-12.9$ & 4.7 & 0.0 \\
$13.0-15.9$ & 13.9 & 4.8 \\
$16.0-18.9$ & 2.3 & 0.0 \\
$19.0-21.9$ & 2.3 & 0.0 \\
22 and above & 4.7 & 4.8 \\
Total & $\mathbf{1 0 0 . 0 \%}$ & $\mathbf{1 0 0 . 0 \%}$ \\
\end{tabular}




\section{Research productivity of rice scientists}

The research productivity of rice scientists in the two institutes calculated by using their research output values as per the two ranking methods is presented in Table 9. It shows that the two methods would not make much of a difference as the scientists have been grouped into different score ranges.

However, the number of scientists in the productivity range of $7.0-9.9$ and $22 \&$ above increased with Method II for both countries where high weightage was given to the work published locally. Therefore, the figures calculated under Method II were used for calculation of $\%$ of scientists in the different productivity score ranges and the results are presented in Table 10. Further, according to Arunachalam ${ }^{18}$, the CAB Abstracts 1998 shows that unlike in biological and physical sciences, most papers in agricultural research in India are published in Indian journals indicating the locality specific nature of agricultural research. The author reported that out of a total 8157 papers published by the Indian researchers; more than $78 \%$ are published in the Indian journals. This reiterates the fact that for publication of research in agriculture, it is the local peer reviewed journals that should be given more weight age.

CRRI (India) has the highest \% of scientists (30.2\%) in the research productivity range of $4.0-6.9$ whereas RRDI (Sri Lanka) has the highest \% of scientists $(33.3 \%)$ in the research productivity range of $1.0-3.9$ (Table 10). Both India and Sri Lanka share similar \% of scientists in the research productivity range of 22 and above. However, $30 \%$ of scientists in the CRRI (India) has research productivity value of above 10 compared to only $10 \%$ of scientists with the same value in RRDI ( Sri Lanka).

MRP for each country is presented in Table 11. The difference in MRP (2.99) measured for the rice scientists in the CRRI (India) and the RRDI (Sri Lanka) was significant at $1 \%$ level $(\mathrm{p} \leq 1)$ based on the t-test conducted.

Further analysis of the data on research publications indicated that $65 \%$ of Indian scientists believed that "publish or perish" should be the criteria for their

Table 11: t-test for significance for research productivity

\begin{tabular}{lc}
\hline Country & Mean research productivity \\
\hline CRRI (India) & 8.19 \\
RRDI (Sri Lanka) & 5.20 \\
Difference & $2.99 * *$
\end{tabular}

** Significant at $1 \%$ level $(\mathrm{p} \leq 1)$ promotions compared to only $28 \%$ of Sri Lankan scientists who had the same view. This attitudinal difference was significant at $5 \%$ probability level. However, nearly $50 \%$ of Sri Lankan scientists neither agreed nor disagreed with this statement. The direct interviews with the Indian scientists revealed that they had a very good choice of refereed local scientific journals for publication. In particular, India publishes a journal devoted to rice research which is a policy measure implemented towards professionalization of rice research.

Even though the scientists in Sri Lanka have made good progress in rice research, publication of research by them was far behind. Compared to rice scientists in CRRI (India), only a few rice scientists in RRDI (Sri Lanka) had PhDs at the time of the survey. Since PhD training is essential for conducting independent research, this study indicates a policy insight that the opportunities for $\mathrm{PhD}$ level training must be provided to the Sri Lankan rice scientists. The study also revealed that research publications was not the primary criterion for promotion of NARS scientists in Sri Lanka and hence many rice scientists were not keen to publish their research. Rice scientists at RRDI (Sri Lanka) also indicated that they did not have much choice of refereed local journals for publication.

Sri Lankan scientists in the NARS were critical about a National Award Scheme based on international publications. They were of the view that agriculture is a locally specific, climatologically limited and culturally biased subject, and therefore, the refereed local publications should be given more weight when evaluating research productivity. The scientists in the Indian NARS also had the same view on this aspect. This is an issue to be considered when policies are adopted for evaluation of agricultural scientists for national awards.

The study also indicated that rice scientists in Sri Lanka should be encouraged to publish their research results and that they should be provided with facilities for easy access to scientific journals. In this context, timely publication of at least a few refereed local scientific journals is a must. The local scientific community may also be provided with proper guidance for publication of research through training sessions and workshops.

\section{CONCLUSION}

As CRRI (India) is a well established and developed research institute in terms of size, number of qualified rice scientists working in the institute and the available laboratory facilities, a comparison of research productivity between CRRI (India) and RRDI 
(Sri Lanka) could be biased. However, the results of the present study show that when research productivity of rice research scientists is evaluated through their publication output, the contribution of rice scientists in CRRI(India) is significantly higher than that of the rice scientists in RRDI(Sri Lanka). The possible reasons for the higher research productivity of Indian scientists were: a) Publication of research is the most essential criterion for promotion and career development of Indian scientists; b) Many Indian journals are available for publication of research including a separate journal devoted for publication of rice research; and c) The majority of Indian rice scientists hold $\mathrm{PhD}$ degrees which is essential for conducting independent research. The study also indicated a policy insight towards training Sri Lankan rice scientists up to $\mathrm{PhD}$ level to achieve higher research productivity.

\section{Acknowledgement}

Since this study was part of the research towards the $\mathrm{PhD}$ programme of the author, close supervision by Prof. V.V.Krishna, Chairman, Centre for Studies in Science Policy, Jawaharlal Nehru University, New Delhi, India and Dr Mruthyunjaya, Former Director, National Centre for Agricultural Policy Research, Indian Council of Agricultural Research, New Delhi, India is gratefully acknowledged. The author is thankful to Dr B.N. Singh, Former Director, CRRI, India and Dr D. S. de Z. Abeysiriwardene, Former Director, RR DI, Sri Lanka for the cooperation extended and to all the scientists and research administrators in the NARS of the two countries who took part in this study. The Swedish International Development Cooperation Agency (Sida) is thankfully acknowledged for the financial support.

\section{References}

1. Merton R.K. (1968). The Mathew effect in Science. Science 159 (3819):56-63.

2. Fox M.F. (1983). Publication productivity among scientists: a critical review. Social Studies of Science 13: 285-305.
3. Lehman H.C. (1953). Age and Achievement. Princeton University Press, New Jersey.

4. Over R. (1982). Does scholarly impact decline with age? Scientometrics 13:207-215.

5. Herbstain F.H. (1993). Measuring "publications output" and "publications impact" of the faculty members of a university chemistry department. Scientometrics $\mathbf{2 8}$ (3):349-373.

6. Pelz D.C. \& Andrews F.M. (1976). Scientists in organizations: Productive Climates for Research and Development. Institute for Social Research, Ann Arbor, University of Michigan, MI 48109, USA.

7. Wickremasinghe Seetha.I. (2004). National Agricultural Research Systems (NARS) in India and Sri Lanka: a study of organization, scientific community and their contribution to rice research. PhD Thesis, Centre for Studies in Science Policy, Jawaharlal Nehru University, New Delhi, India.

8. Allison P.D. (1980). Process of Stratification in Science. Arno Press, New York.

9. Skiff A. (1980). Towards a theory of publishing or perishing. The American Sociologist 15: 175-183.

10. Gaston J. (1978). The Reward System in British and American Science. John Wiley, New York.

11. Gustin B.H. (1973). Charisma, recognition and motivation of scientists. American Journal of Sociology 78:11191134.

12. Cole S. \& Cole J. (1967). Scientific output and recognition. American Sociological Review 32:377-390.

13. Scott Long J. \& Mc Ginnis R. (1981). Organizational context and scientific productivity. American Sociological Review 46: 422-442.

14. Chakravarthy R. (1986). Productivity of Indian women scientists. Productivity XXVII (3): 259-269.

15. Levin S.G. \& Stephan P.E. (1991). Research productivity over the life cycle: evidence for academic scientists. The American Economic Review 81(1): 114-132.

16. Yin R.K. (1994). Case Study Research: Design and Methods, Second Edition. Sage Publications, Thousand Oaks, California, USA.

17. Wengraf T. (2001). Qualitative Research Interviewing. Sage Publications Ltd. Bonhill Street, London.

18. Arunachalam S. \& Umarani K. (2001). Mapping agricultural research in India: a profile based on CAB Abstracts 1998. Current Science 81(8): 896-906. 